\title{
Sistematik Siyasi Bir Anlayış Olarak Biyosiyaset
}

\author{
Biopolitics as a Systematic Political Understanding
}

Feysel TAŞÇIER *

Öz: Biyosiyaset dâhilinde yaşam ve ölüm olgusu pek çok açıdan siyasi egemenlik tarzı ile doğrudan ilişkilidir. Siyasal iktidarın kendisini yaşatmak için uyruklarını belirli bir bütünsellik içinde tutma çabası, yasal kurumsal bir düzenlemeyi gerektirir. Nüfusun dağıtım ve düzenini hesaplayıp koordine eden egemen iktidar, belirli bir yerleştirme pratiği ile işler. Bu pratiğin modern yönelimdeki siyasetini oluşturan temel yapı, belirli diyagramlar temelinde işleyen yapı olarak biyosiyaset kanalıyla gelişir. Bu inceleme, biyosiyaset çerçevesinde klasik ve modern siyaset ve egemenlik biçimini karşılaştırıp analiz eden iki çağdaş filozof Foucault ve Agamben'in görüşlerinden hareket etmektedir.

Anahtar sözcükler: Biyosiyaset, Hayat, Ölüm, Sınır, Hukuk, İnsan

Abstract: The fact of life and death in the scope of biopolitics is in many respect directly related to the manner of political power. For political power to survive and to keep its subjects under a certain frame of totality, it requires a legal institutional arrangement. The government in power that counting and coordinating the distribution of population functions as a certain practice of positioning. The fundamental structure that constitutes the modern politics of this practice is developed by means of biopolitics, as the structure functioning on the ground of certain diagrams. This study begins with the ideas of two contemporary philosophers Foucault and Agamben, as they compare and analyse classical and modern types of politics and sovereignty within the framework of biopolitics.

Keywords: Biopolitics, Life, Death, Border, Law, Human

Biyosiyaset, modern siyasetin ve egemenlik tarzının sistematik bir ifadesi olarak ortaya çıkar. $\mathrm{Bu}$ tarz bir siyaset anlayışının temel nesnesini yaşam oluşturur. Yaşam üzerinde toptan bir kuşatmayı hedefleyen böylesi bir siyaset tarzı, insanı ve onun yaşamını kapitalist üretim ve tüketim alışkanlıklarının bir objesi/nesnesi haline getirip, belirli verimlilikler ağı içinde hesaplayıp denetlemeyi öngören bir anlayış olarak ortaya çıkar.

Biyosiyaset, bir başka bakımdan biyoiktidar ve egemenliği olarak ortaya çıkar. Biyoiktidar kolektif şiddet kadar bireyselleştirilmiş şiddet teknikleriyle de çalışır. "Başka bir deyişle biyosiyaset, yaşamı yeniden düzenlemeden ölüm üzerinde mutlak bir hakka kadar uzanan sistematik bir anlayış olarak ortaya çıkar" (Hardt \& Negri 2004, 37). Biyosiyaset tarzının karşısında klasik egemenlik biçimini temsil eden ve temel nesnesi ölüm olan siyaset tarzı yer alır. Bu inceleme, biyosiyaset çerçevesinde klasik ve modern siyasetin egemenlik biçimlerini karşılaştırıp analiz eden iki çağdaş filozof Foucault ve Agamben'in görüşlerinden hareket etmektedir. Bu

\footnotetext{
*Doç. Dr., Ankara. feysel.tascier@gmail.com
} 
doğrultuda öne sürülen temel yaklaşım; yaşamın ve ölümün belirli bir siyaset biçiminde gelişip bireysel anlamda insanın "normal insan" tasarısı içinde yeniden biçimlendirilmeye çalışıldığını ileri sürmektedir.

Biyosiyaset içinde düşünüldüğünde, yaşam ve ölüm gibi birbirini tamamlayan iki olgunun siyaset ile birleşmesi, egemenlik stratejilerinin bir yansıması olarak gelişir. Varoluşsal özelliği içinde yaşam da ölüm de siyasal egemenliğin stratejisi içinde herhangi bir değer ifade etmemektedir. Ölümün "olumsuz", yaşamın ise "olumlu” bir değer olarak görülebileceği bakış açısı siyaset ile ilgisi içinde farklı anlamlardaki kimi daha başka değerlerle izah edilir. Söz konusu değerlendirme biçiminde, egemen kılınması talep edilen kimi anlayışlara göre, ölüm olgusu kutsanan/yüceltilen bir değer olarak ortaya çıkarken, yaşam "olası en iyi dünyanın" olgusu biçiminde düşünülerek ertelenen bir sürecin konusu haline getirilir.

Böylelikle belirli bir siyasetle gelişen zeminde temelsiz gibi görünse de, yaşam ve ölüm belirli durumlarda -biyosiyaset içinde- bir ikilem olarak ortaya çıkar. Siyasetin insan yaşamını kolaylaştıran, organize edip yeniden kuran yapısı içinde ölümün siyasetle birleştiğini öne sürmek bu ikilemin bir yüzünü oluşturur. İkilemin diğer yüzünde yaşam adına belirli yaşamlara mal olan ve kaçınılmaz biçimde ölüme güdülenmiş klasik siyasetin şiddet ve ölüm üreten yapısı yer alır. Her iki durumda da, siyasallaştırılmış bir dünyanın insanı amaç olmaktan ziyade araç gören yapısı, genel olarak siyasetin özel olarak da egemenlik stratejilerinin güdümlü ve anti hümanist bir anlayış içinde hareket etmesinin bir sonucudur. Bu durum siyasal alanın insan merkezli değil, daha çok onu belirli bir tözsellik etrafında tutup araç kılan siyaset anlayışı ile ilgilidir.

Yaşam ve ölüm ekseninde siyasal alanın geçmişten bu yana süregelen yapısına baktığımızda ise, birbirinden yapı ve amaç itibarıyla farklı iki paradigmanın hâkim olduğunu görürüz. Egemenlik stratejisi ve biçimiyle de doğrudan bağlı görünen yapıda siyaset tarzı, klasik ve modern egemenlik biçimi olarak birbirinden ayrılır.

"Egemenlik sürecinin ilk evresini oluşturan klasik dönem toprak temelli olarak işlerken, kralın hükümran bedeni bütün bir ulusun bedenini temsil eder. Buna karşın, klasik dönemden farkl olarak modern dönem ise egemenlik stratejisinin yeni fetih alanını topraktan ziyade insana ve onun yaşamına yönlendirir. Insanın bedenini yönetip onu ele geçirmeyi hedefleyen bir olgu olarak ortaya çıkan bu egemenlik biçimi biyosiyaset kanalıyla gelişir. Özellikle onsekizinci yüzylldan bu yana, egemenlik stratejisinin hakiki nesnesinin nüfus haline geldiğini imleyen bir olgu olarak biyosiyaset, devletin her şeyden önce insanlara nüfus olarak göz kulak olma sürecini betimler. Biyosiyaset kanalıyla iktidar, canlı varlıklar üzerindeki egemenliğini, onların canlı varlık oldukların kabul ederek uygulayan bir biyosiyasettir. Foucault'ya göre, nüfus devletin kendi çıkarı için göz kulak olduğu şeyden öte olmadiğından, devlet, gerek duyduğunda nüfusu katledebilir. Böylece biyosiyasetin tersi thanatos siyasete -ölüm siyasetine- dönüşür” (Foucault 2005, 121).

Yaşam ve ölüm üzerinde mutlak bir erk ve yetkiyle ortaya çıkan egemenlik biçimi, egemene bunu "meşru" bir hak olarak sunuyordu. Egemenin gerek klasik gerekse de modern tarzında işleyen bu süreç, bir bütün olarak bir ulusun ve üyelerinin hayat ve ölüm hakkının kararını egemene devrediyordu. "Bütün uyrukların yaşamı -herkesin ölümü gerekse bile- hükümdarın yaşamına aktarılmıştır. Gerçekte hükümdarın yaşam ve ölüm üzerinde mutlak bir hakka sahip olması, ölümü isteme hakkıyla ortaya çıkmaktadır. Böylelikle ölüme çağrı niteliğindeki istemin yerine getirilmesi, hükümdarın yaşam üzerindeki iktidarının göstergesi olarak ortaya çıkar. Foucault'nun ifade ettiği gibi, yaşam ve ölüm üzerindeki hak diye söze geçirilen, gerçekte yaşamına el koyma ve yaşamına izin verme hakkıydl. Bu hakkın da simgesi kılıçt. İktidar bu 
bağlamda her şeyden önce el koyma hakklydl. Bu hak, yaşamı ortadan kaldırmak için onu ele geçirme ayricalı̆̆gyla üstün bir konuma yükseliyordu” (Foucault 1990, 135-136). Agamben'e (1999, 82) göre "böyle bir hak, kendisini her şeyden çok ölümden yana kullanması bakımından, tanımı itibariyle, asimetriktir; yaşamla sadece dolaylı olarak, öldürme hakkını kullanmada çekimser kaldiğında ilgilenir. Foucault'nun egemenliği ölmeye terk etmek ve yaşamasına izin vermek formülüyle tanımlamasının nedeni budur".

Foucault, iktidar mekanizmasının yaşam ve ölüm üzerindeki mutlak güç ve belirleyen olarak ortaya çıkışını şu şekilde değerlendirir: "Tasarruf hakkı, bu mekanizmaların en önemli biçimi olmaktan çıkıp, boyun eğdirdikleri güçleri klşkırtma, güçlendirme, denetleme, gözetleme, çoğaltma ve düzenleme işlevlerine sahip olan parçalar içinde bir parça haline; üretmeye ve bu güçleri silmek, eğmek ya da yok etmek yerine güçlendirmeye ve düzenlemeye yönelik bir iktidara dönüşür. Ölüm hakkl, o andan itibaren yaşamı yöneten bir iktidarın gerektirdiklerine doğru kaymaya, ya da en azından bunlara dayanmaya ve bunların taleplerine uymaya yönelecektir. Hükümdarın kendini savunma ya da kendisinin savunulmasın talep etme hakkı üzerine kurulan bu ölüm, toplumsal bünye için yaşamın sağlama, ayakta tutma ya da geliştirme hakkının öbür yüzü olarak ortaya çıkacaktır. Bununla birlikte savaşlar hiçbir zaman ondokuzuncu yüzyıldan bu yana yapılanlar denli kanlı olmamış, hatta bütün oransal farkları dikkate aldiğımız takdirde bile, bu zamana değin hiçbir rejim kendi nüfusu üzerinde böylesi soykırımlar uygulamamıştır. Ama bu harikulade ölüm hakkl, artık kendini, yaşam üzerinde olumlu biçimde etki gösteren, yaşamı yönetmeyi, yükseltmeyi, çoğaltmayı ve bu yaşam üzerinde kesin denetimler ve bütüncül düzenlemeler yapmayı iş edinen bir iktidarın tamamlayıcısı olarak sunar" (Foucault 2003, 100101).

Yüzyılımızda yaşanan kitlesel savaşlar, soykırımlar ve terör biçiminde gelişen şiddet eylemleri, geçmişte yaşanan kıyıcı ve şiddet dolu eylemlerinden çok farklı şekilde gelişmektedir. İdeolojik kutuplaşmaların, dinî ve siyasi sembol ve aidiyetlerinin etrafında biçimlenen kimlik ve daha başka simgesel değerlerin adına yapılan şiddet hareketleri milletleri - halkları birbirine 'kutsal'lık atfedilen değerleri adına birbirlerini 'meşru' savaşları çıkarmaya sevk etmiştir. Böylelikle kendi hayatı için ötekini öldürmeyi, yok etmeyi hedefleyen yok edici bir biyosiyasi anlayışın "meşru”" temellerinde halklar ölümcül bir oyuna hazır hale getirilmiştir.

Bu durum Foucault' a göre, “katliamların 'yaşamsal' olma düşüncesinden ileri gelmektedir. Onca rejim, yaşamın, yaşamı sürdürmenin, bedenlerin ve ırkın yöneticisi olma sıfatıyla onca insanı öldürterek onca savaşı sürdürebilmiştir ve çemberi kapatmamızı sağlayan bir dönüşle, savaş teknolojisi bu rejimleri, top yekün yok etmeye ittikçe, savaşları başlatan ve bitiren kararlar da gittikçe yaşamı sürdürme sorununa göre düzenlenir olmuştur. Günümüzdeki nükleer durum bu sürecin varış noktasında yer alır. Bir halkı toptan ölüme mahkûm etme gücü, bir başka halkın varlı̆̆ını sürdürmesini sağlama gücünün öbür yüzüdür. İlke şudur: Meydan savaşlarının dayandiğı taktik olan yaşayabilmek için öldürebilme fikri, devletlerarası bir strateji ilkesine dönüşmüşü̈r. Söz konusu olan, egemenliğin hukuksal varlığı değil, bir halkn biyolojik varlığıdır. Ĕ̆er soykırım modern iktidarların düşlediği bir şeyse, bu, eski öldürme hakkının günümüzde geri gelmesinden değil, iktidarın yaşam, tür, ırk ve kitlesel nüfus olayları düzeyinde yer almast ve kendini orada göstermesindendir" (Foucault 2003, 101).

Egemenin yaşam ve ölüm üzerinde mutlak bir güç olmasının anlamı, siyasi iktidarın/egemenin kendi yurttaşını bizzat yaşamı hakkında herhangi bir tasarruf ve yetkiden uzak tutması demekti. Başka bir deyişle hepimizin, herkesin yaşamı egemenin erk'in "keyfi kararıyla" belirlenen bir süreç içinden geçerek gelişiyor. Buna göre, her hayat, herkes gerek klasik dönemde gerekse modern egemenlik anlayışının döngüsünde savaş ve şiddet çarkı içinde birer sayısal 
veriye ve araca dönüştürülmüştü. Egemen otoritenin birincil olarak denetimi altındaki nüfusu güvenlik içinde yaşatma hakkı toplumsal sözleşmenin ruhu içinde vurgulanan bir ihtiyacı yansıtmaktaydı. Yaşatmaya koşullanan böylesi bir yönelimin şiddet ve ölüm üretebilen bir aşamaya gelmiş olmasının çelişkisi, siyasetin yeni güvenlik paradigmalarının değişmesi ve stratejik boyutu ile ilgidir. Bu durumun yeni dengelere ve güvenlik paradigmasına göre boyut değiştirmesi, bazı soruları da beraberinde getirmektedir.

Buna göre ilkin akla gelen soruları şu şekilde özetlemek mümkündür: Egemen erk'in kendi kararıyla yurttaşını ölüme hazır olacak şekilde yaşatma ve öldürme hakkının dayanağı nedir? Yine sözleşme teorisine bakıldığında, güvence olarak gelişen siyasi birliktelik fikri ile böylesi sistematik öldürme çarkı arasında bir çelişki yok mudur? Yaşam ve ölüm hakkında keskin bir hükme sahip egemen kararı her türlü hayat hakkında bu kadar keskin bir yere yerleştiren düşüncenin kökeni ve meşruiyeti nereye dayandırılabilir?

Yaşam ve ölüm üzerinde teknikleştirilmiş ve içsel kılınmış olan modern biyosiyasi anlayışın izlerini elbette Antik Yunan'da ve insanı "siyasal bir varlık" olarak tanımlayan Aristoteles'in görüşlerinden de hareketle anlamak mümkündür. Biyosiyasi düşünce modern egemenlik tarzının bir ifadesi olarak ortaya çıkıp gelişse de, bir siyasi anlayış olarak tarihsel dayanaklardan beslenmektedir.

Siyasal egemenliğin geldiği en üst aşamayı gösteren biyosiyaset, modernliğin geldiği eşik noktasını ifade ederken nesnesi doğrudan yaşamın kendisidir. Ancak, yaşam ile söz edilen şeyin açık kılınması gerekmektedir. Zira Antik Yunan'da “yaşam zoē ve bios (Zoē, bütün canlı varlıkların doğal yaşamını imlerken, bios bir bireyin belirli yaşam tarzına işaret eder) olarak birbirinden farklı iki terimle karşılanır. Biyosiyasetin üzerinde döndüğ̈̈ yaşam ile kastedilenin daha çok zoē mu yoksa bios mu olduğu yönündeki tartışmada hem Foucault hem de Agamben bunun zoē olduğu konusunda birleşirler. Bu anlamda, zoē ile bios arasindaki Antik yorum hakkında ilkin Aristoteles'in Politika'da dile getirdiği birtakım ayrımlara bakmak gerekmektedir. Siyasal tarihte uzun süre insan Aristoteles'in vurgusuna bağll kalarak -siyasal yaşamınetrafinda döndüğ̈̈ yaşamın bios ile temsil edildiğinden hareketle, zoē'dan olan farkını göstermeye çalışmıştır. Aristoteles de Politika'da bu ayrımın farkında olarak polisin amacının iyi bir yaşam sürmek olduğunu belirterek bios'un siyasallı̆̆ın öncelikli yeri ayırlyordu. Bu çerçevede Aristoteles'e göre iyi yaşam, hem bireysel anlamda bütün insanların hem de ortak olarak gütmüş oldukları en yüksek amacı oluşturur. Böylelikle doğal yaşam gerçeğinin kendisindeki iyi yan, insanların bir araya gelip siyasal topluluklarını kurmalarının yolunu açmıştır" (Aristot. Pol. 1278b 20-30). “Ortak bir yarar etrafinda polis 'te şekillenen bios'un siyasalliğına karşıllı, doğal yaşamı imleyen zoē, kesin bir şekilde polisin dışında tutularak oikos'un alanına dâhil edilmiş oluyor. Aristoteles'e göre, zoè anlamında insanın oikos'a çekilmesi yaşamı idame ettiren üretici yanından ileri gelmektedir" (Aristot. Pol. 1252a 25-35). Bu çerçevede, Aristoteles ideal bir toplumun amacını zoē ile bios arasındaki bu ayrımdan hareketle kurarken; insanın politikon zōon olarak tanımlamasında da bios'un siyasallığının önemine vurguda bulunur.

Agamben (1998, 2-3) bu belirlemede "ince bir ayrıma işaret ederek, Aristoteles'in ifade ettiği siyasallığın tam anlamıyla canlı varlığın bir sıfatı değil zōon cinsini belirleyen spesifik farklardan biri olduğunu belirtir”. Nitekim Aristoteles de siyasal hayvan olarak insanı diğer canlılardan ayıran bu niteliğe işaret ederek, "insanın siyasal varlık olmasının konuşabilme yetisi sayesinde -diğer canlıların ses çıkarmalarından farklı biçimde- yararlı ve zararlı olanı, doğru ve yanlışı ya da adil olan ile olmayanı birbirlerine bildirmelerine yaradiğını belirtir. Isste bu da bir aile ya da kenti meydana getiren ortak çıkarın oluşmasın să̆layarak siyasal topluluğun önünü açar" (Aristot. Pol. 1253a 8-18). Foucault "modern çağın başından bu yana, doğal 
yaşamın (zoē) siyasal iktidarın mekanizması içine taşındığından hareketle, siyasetin günümüzde biyosiyasete dönüştügünü ifade eder. Foucault'ya göre, insan uzun bir süre boyunca Aristoteles'in tanımladığı gibi diğer canlılara ek olarak siyasal varoluş kabiliyeti olan bir hayvan olarak düsünülmüş̧ür. Oysa modern insan, canlı bir varlık olarak yaşamını kendi siyaseti dâhilinde söz konusu eden hayvandır" (Foucault 1990, 143).

Özellikle modern çağda çeşitli tekniklerle gelişen biyosiyasi yönetim anlayışı, insanı bedensel bir varlık olarak siyasal yönetimin nesnesi olarak adeta yeniden tanımlar. Klasik dönemin mülkiyet temelli egemenlik anlayışının yerini nüfus temelli işleyen egemenlik alır.

Gelinen bu süreci Agamben, egemenlik ilişkisinde ortaya çıkan durumu en sofistike siyasal tekniklerin kullanılmasıyla başarılanın insanın hayvanlaştırılması olduğunu belirterek açıklar. Öyle ki, aynı anda hem yaşamı korumak hem de bir soykırıma yetki vermek mümkün hale gelmiştir. Agamben'e göre, "uysal bedenleri yaratan söz konusu yeni biyosiyasi iktidarın ulaştı̆̆ disiplinci denetim olmasaydl, kapitalizmin gelişimi ve zaferi mümkün olmayacaktı. O halde, buraya kadarki gelişen yeni süreç tam olarak şu şekilde ifade edilebilir: Aristotelesçi yorumla insan, zoē'dan ziyade bios'un özelliği olarak görülen siyasal varoluş kapasitesi, modern çağdan bu yana dönüşüme uğramıştır. Agamben bu dönüşüme ilk dikkat çeken kişinin Arendt olduğunu dile getirir. Ona göre, Arendt İnsanlık Durumu eserinde ortaya koyduğu kadartyla animal laborans'l ve yalın biyolojik yaşamı modernliğin siyaset sahnesinin merkezine yerleştiren analizi Foucault'dan önceye denk gelir. Arendt Insanlık Durumu eserinde, modern toplumlardaki siyaset alanının dönüşüm ve çöküşünü, doğal yaşamın siyasal eylem karşısındaki önceliğine yüklüyordu” (Agamben 1998, 3-4).

Özellikle yüzyılımızda giderek çeşitlenip büyüyen siyasal sorunlar modern egemenlik tarzının bir yansıması olan biyosiyasi anlayışın bir sonucu olarak görmek mümkündür. Agamben'e göre, “Biyosiyasi paradigmada zoē'nin (yalın yaşamın) siyasal alana dâhil edilmesi olarak gelişen biyosiyaset, modern siyasal düşüncenin klasik düşünceden radikal kopuşuna işaret eder. Siyasal alanda yaşanan bu dönüşüm, tarihte benzeri yaşanmamış kolektif şiddet eylemlerinin kapısını aralamış; özellikle yüzyılımız Nazi Almanya'sı ve Stalin Rusya'sında vücut bulan şiddet histerilerinin önayak olduğu büyük kitlesel kıyımlara neden olmuştur. Agamben, modern siyaset alanında ortaya çıkan daha başka kimi kategorilerin (săg / sol, özel / kamusal, mutlakiyetçilik / demokrasi, vb.) günün birinde yitirdikleri anlamlara veya ortadan kalkıp kalkmayacaklarına karar verebileceğimiz yerin biyosiyasi ufkun kendisi olduğunu düşünür" (Agamben 1998, 4).

Foucault, iktidarın öznelerin bedenlerine dek nüfuz etmesini ve onların yaşam tarzlarına müdahalede bulunduğunu belirterek bu sürecin gelişim tarihini şu şekilde ifade eder: "Bireylerin bedenlerini, davranışlarını hedefleyen bir teknoloji olan ve iktidarın bireyleştirici teknolojisi diye adlandirlan şey, genel hatlarlyla, bir tür siyasi anatomidir. Onyedinci ve onsekizinci yüzyıllarda ortaya çıkmıs iktidar teknolojileri familyası; biraz daha geç, onsekizinci yüzyılın ikinci yarısında ortaya çıkan ve özellikle İngiltere'de (birinci familyanın, Fransa'nın yüzkarası olarak, özellikle Fransa'da ve Almanya'da gelişstirildiğini söylemek gerekir) gelişir. Bir başka iktidar teknolojileri familyası daha var: Bireylerle birey olarak ilgilenmeyen, ama tersine nüfusla ilgilenen teknolojiler. Başka deyişle, onsekizinci yüzyıl şu temel şeyi keşfetti: İktidar sadece tebaa üzerinde uygulanmaz; hükümran ile tebaanın var olduğunu söyleyen monarşinin temel tezi buydu. Iktidarın nüfus üzerinde uygulandiğ keşfedilir. Peki, nüfus ne demektir? Bu sadece kalabalık bir grup insan demek değil; biyolojik süreçlerin ve yasaların nüfuz ettiği, emrettiği, yönettiği canlı varlıklar demektir. Bir nüfusun doğum oranı, ölüm oranı vardır, bir nüfusun yaş eğrisi, yaş piramidi, hastalanma hali, sağllk durumu vardır, bir nüfus yok olabilir veya tersine, gelişebilir" (Foucault 2005, 151-152). 
Siyasi iktidarın nüfus üzerinde her türlü denetim ve kontrol aracı olarak ortaya çıkması ve her bir bedenin egemen erkin eyleminin birer nesnesi olarak yeniden kurulması on sekizinci yüzyıl ve sonrasında bir başka deyişle modern egemenlik tarzının bir sonucuydu. Yaşamın iktidar alanına bu şekilde dâhil olmasını Foucault, insan toplumlarının tarihindeki en önemli değişimlerden biri olarak görmektedir. Değişen iktidar ve egemenlik biçimi, tebaadan yurttaşa vatandaşa 'yükselttiği' bireye hükmetme tarzı ve tekniğini uygularken, canlı beden olarak insan -ister tebaa ister yurttaş olsun- biyoiktidarın bir nesnesi olma kaderinden kurtulamıyordu. İktidar ister klasik isterse de modern tarzda gelişsin canlı bedenler olarak insan nesnesine ikiyüzlü bir çerçeve içinde yöneliyordu.

Agamben'e göre, iktidarın bu iki yüzünün bir noktada birleştiği yer bulanıktır. Bu birleştirme noktası veya belirsizlik mıntıkasının tam olarak neresi olduğunun aydınlatılması gerekmektedir. Agamben, La Boétie’dan bu yana iktidarın ortaya çıkışında birtakım öznel süreçlerin oynağ1 rolün gerçekliğine rağmen, siyasal alan gibi hassas bir alanda öznel süreçlerin nesnel iktidarla ilişkiye geçtiği yerin tam olarak neresi olduğunun bilinmesinin önemine işaret eder. Ona göre, “Foucault'nun çalı̧̧malarında böyle bir mantıksal düşünme çizgisi mevcut olmasına rağmen gerek Foucault'da gerekse de iktidar sorunu ile ilgili inceleme yapan Batıl diğer düşünürlerin farkl perspektifteki çalışmalarında birbiri ile birleşemeyen 'kör bir nokta' vardır. İşte tam da burası, Agamben'in ele aldiğı hukuksal - kurumsal iktidar modeli ile biyosiyasal iktidar modeli arasındaki örtük kesişme noktasını oluşturuyor" (Agamben 1998, 5-6). Bu iki modeli birbirinden ayırmanın olanaksızlığına işaret eden Agamben, burada saklı bile olsa egemen biyoiktidarın "orijinal çekirdeğì" olan şeyi, yalın yaşamın (zoē) siyasal alana dâhil oluşu olarak görmek gerektiğini öne sürer.

\section{III}

Foucault ve Agamben'in analizlerini, “zoè'nin (yalın yaşamı) siyasal alanın merkezine çekilmesini bios’un zoē’yu içermesi olarak da okumak mümkün. Aristoteles’ten bu yana siyasal yaşamı imleyen bir olgu olarak ortaya çıkan bios, iyi bir yaşam sürmenin olanağı olarak görülürken; yalın yaşam (zoē) siyasal alandan dışlanmıştı. Biyosiyasi paradigma ile birlikte, daha önce siyasal alandan dışlanan yalın yaşam (zoē) siyasal alanın bir parçası haline gelmiştir. Agamben, Batı siyasetinin ilkin ev yaşamın polis yaşamından neden dışladiğı -ki bu dışlama aynı zamanda bir içermedir- sorgulanmasının gerekliliğine vurgu yaparken; yaşamın dışlanarak içerilmesini siyaset ile yaşam arasındaki iliş̧kide görmektedir" (Agamben 1998, 7).

Agamben'e göre: “Yaşam sahibi olarak doğan, fakat özde iyi yaşam hedefiyle yaşayan biçimindeki spesifik ibare, sadece varlı̆̆ın (ousa) doğumu (ginomenē) içermesi doğal olarak değil; aynı zamanda zoè'nin polisten içlenerek dışlanması (exeptio) olarak da okunabilir. (...) Agamben'e göre, yalın yaşam ile siyaset arasındaki ilişki, insanı 'konuşan canlı varlık' olarak tanımlayan metafiziğin bu tanımının phonē ile logos arasındaki bağlantısal iliş̧ki ile aynıdır" (Agamben 1998, 7-8).

Buna göre, "canlı varlık hangi şekilde dile sahiptir?" sorusu tam anlamıla "yalın yaşam hangi şekilde poliste yer alır?" sorusu ile eş anlama gelir. Canlı varlığın logos'a sahip olması, logos'ta kendi sesini bastırması ve korumasıly olur; tam da polis'te yer almasının, kendi yalın yaşamının polis'te, bir istisna olarak, dışlanmasıyla olduğu gibi. Buradan hareketle, Agamben siyasetin canlı varlık ile logos arasındaki ilişkinin gerçekleştiği eşik mekânı işgal ettiği sürece, Batı metafiziğinin temel yapısı olarak karşımıza çıktığını ifade ediyor. Yalın yaşamın "siyasallaştırılması”yla yapılan şey, yaşayan insanın insanlığına karar vermektir. Agamben'e göre, bu görevi yerine getirirken modernliğin yaptığı iş, metafizik geleneğin özcü yapısına olan bağlılığını göstermekten başka bir şey değildir. Batı siyasetinin temel ikiliğinin dost - düşman 
ayrımı üzerine kurulduğunu dile getiren Schmitt'in tersine Agamben, günümüzde bunun yerini "yalın yaşam / siyasal varoluş, zoē / bios ve dışlama / içerme ikiliklerine bıraktığını" belirtiyor (Agamben 1998, 8).

Agamben göre, modern siyaseti tanımlayan şey, “ne zoē'nin polise dâhil edilmesi -ki bu eski bir durumdu- ne de yalın yaşamın, devlet iktidarının hesaplamalarının temel öznesi haline dönüşmesidir. Bütün istisnaların kural olması sonucu ile birlikte Yalın yaşamı, siyasal alanın marjinlerinde konumlayan bir olgu olarak gören Agamben, gün geçtikçe bunun siyasal alanla örtüşmeye başladı̆̆ını ifade eder. Yalın yaşamın siyasal alanın ufkunda görünmesiyle birlikte, dışlama /içine alma, dı̧̧arı / içeri, bios / zoē ve hak ile olgu durumları indirgenemez bir belirsizlik mintıkasına giriyor. Agamben'e göre, bütün siyasal sistemin gizli temelini tesis eden bu belirsizlik noktasında yalın yaşam yer alır" (Agamben 1998, 9).

Agamben, "yalın yaşamın devlet iktidarının canlı bir varlık olarak insanı kendi özgül nesnesi yaptı̆̆̆ disiplin süreciyle birlikte, büyük ölçüde modern demokrasinin doğuşuna tekabül eden bir başka sürecin başlatılmış olduğunu öne sürer. Bu ikinci süreçte, canlı bir varlık olarak insan kendisini artık siyasal iktidarın bir nesnesi olarak değil; bu iktidarın bir öznesi olarak da sunuyor. Iş̧te bu nokta, pek çok açıdan birbirinin karşıtı olan ve birbiriyle sert biçimde çatı̧̧an bu iki süreç, yurttaşın yalın yaşamı bağlamında, insanlı̆̆ın yeni biyosiyasal bedeni ile birleşiyor" (Agamben 1998, 9). Modernliğin eşiği olarak tanımlanan ve yeni bir egemenlik yapısını gösteren bir olgu olarak biyosiyaset, günümüzde modern demokrasinin kendini klasik demokrasiden ayırdığ 1 bir sürece işaret ediyor. En başından beri modern demokrasi kendisini " $z o \bar{e}$ ' nin doğrulanması ve kurtuluşu" olarak sunarken, kendi yalın yaşamını bir başka yaşam tarzına dönüştürmeye ve deyim yerindeyse, zoèe'nin bios'unu bulmaya çalış1yor. Agamben bu süreci, "modern demokrasinin kendine özgü spesifik açmazının (aporia) ortaya çıktı̆̆ını öne sürerek açılklamaya çalışıyor. Ona göre, modern demokrasi, insanların özgürlük ve mutluluklarını, insanların bağımlılıklarının ve boyun eğmelerinin sergilendiği mekânda -yalın yaşamda- artyor" (Agamben 1998, 9-10).

Yirminci yüzyılda gelinen noktada şunu rahatlıkla ifade edebiliriz ki, demokrasi pek çok kazanıma rağmen insanlığa aradığı mutluluğu ve eşitliği getirmiş değildir. İnsanlığın en büyük felaketlerinden sayılan dünya savaşlarının yarattığı dehşet ve belirsizliklerin giderileceği ve insanlığın vicdanının rahatlatılacağı tarafsız ve eşit bir irade de geliştirilmemiştir.

Totaliter rejim ve yönetimler yıllarca kitlesel kıyımlara sebebiyet vermiştir. Egemen erk emri altındaki nüfusa kıyıcı eylem ve yönelimlerde bulunmuştur. Bir başka deyişle nüfusunu yaşatmaya değil kendini yaşatmaya odaklanmış ve bireysel çılgınlıklarını dizginleyecek herhangi bir irade mekanizması da gelişmemiştir. Böylesi bir süreci demokrasinin çöküşü veya işlevsizliği olarak da tanımlamak mümkündür.

Genel anlamda, "yalın yaşamın halen siyaset içinde bir istisna olarak, yani dışlanarak içerilen bir olgu olarak var olması süreci devam ediyor. Zoè'nin bios'a -siyasallaştırılması anlamında- katılması olanaklı mıdır? Veya siyaset zaten zoē'nin merkezinde bulunmuyor mu? Agamben'e göre, hem modern totalitarizmin ve hem de kitlesel hedonizm ve tüketim toplumunun biyosiyaseti bu sorulara yanıt vermekten oluşuyor" (Agamben 1998, 11).

Sonuç itibarıyla, yeni bir siyasetin yolunun açılabilmesi, ancak yalın yaşamın içlenerek dışlanması üzerine kurulu olmayan bir siyaset ile mümkün olabilir. Aksi durumda kan ve şiddetin yolunun siyasal alandan tümüyle dışlanması olanaklı olmayacaktır. Biyosiyaset dâhilinde gelişen ve hem yaşam hem ölüm üzerinde mutlak bir hükmetmeyle ortaya çıkan egemenlik tarzı kılık değiştirse de bünyesinde barındırdığı şiddet üretme kapasitesini sadece teknikleştirip araçsal kılmıştır. 
Egemen iktidarın biyoiktidara dönüştüğü bir süreç olarak ortaya çıkıp gelişen biyosiyaset, egemenin bedenini, iradesini ve yetkisini toptan bir ulusun yok olması pahasına her türlü varlığın üstünde gösterip yaşatmaktadır. Şiddet dolu insanlık tarihinde bireysel ve tekil durumların ötesinde kurumsal kılınan biyosiyasetin egemenlik tarzı inceltilmiş, kılık değiştirilmiş ve kendini maskeleyen pek çok sürecin içinde hükmünü sürdürmektedir.

\section{KAYNAKÇA}

Agamben G. (1998). Homo Sacer -Sovereign Power and Bare Life-. Trans.: D. Heler-Roazen. California 1998.

Agamben G. (1999). Remnants of Auschwitz -The Witness and the Archive-. Trans.: D. Heler-Roazen. New York 1999.

Aristot. Pol. (Aristoteles, Politika) Kullanılan Metin ve Çeviri: Aristotle, Politics. Translated by H. Rackham. Cambridge 1998.

Foucault M. (1990). The History of Sexuality. Vol. I. Trans.: R. Hurley. New York 1990.

Foucault M. (2003). Cinselliğin Tarihi. Çev.: H. U. Tanrı̈ver. İstanbul 2003.

Foucault M. (2005). Özne ve İktidar, -Seçme Yazılar 2-. Çev.: O. Akınhay. İstanbul 2005.

Hardt M. \& Negri A. (2004). Çokluk -İmparatorluk Çağında Savaş ve Demokrasi-. Çev. B. Yıldırım. İstanbul 2004. 